\author{
Cristián S. Miranda · Antonio R. Carvajal \\ Paula Venditti
}

\title{
Laparoscopic tubal reanastomosis
}

Received: 16 February 2005/ Accepted: 26 July 2005/ Published online: 8 September 2005

(C) Springer-Verlag Berlin / Heidelberg 2005

\begin{abstract}
Traditionally, tubal reanastomosis has been performed microscopically via laparotomy. The laparoscopic approach has revealed high pregnancy rates comparable with those obtained after microsurgery by laparotomy and yields important advantages such a less postoperative discomfort and fewer complications, no incisional scar, a shorter recovery time, and earlier resumption of normal activities. The one-stitch technique gives a good approximation of the tissues with a shorter operative time and successful results. In this report we present a case of tubal reanastomosis by laparoscopy using the one-stitch technique, which resulted in an intrauterine pregnancy.
\end{abstract}

Keywords Anastomosis - Surgical ·

Surgery $\cdot$ Laparoscopy $\cdot$ Fallopian tubes.

\section{Introduction}

Approximately $1-3 \%$ of the women who undergo tubal sterilization request a reversal $[1,2]$. Current surgical management options include microsurgical technique by laparotomy and laparoscopic procedures. The laparoscopic approach has several important advantages over laparotomy, such as fewer complications, less postoperative discomfort, no incisional scar, a shorter recovery time, and earlier resumption of normal activities [3]. However, laparoscopic techniques are described as being

C. S. Miranda $\cdot$ A. R. Carvajal · P. Venditti

Departamento de Obstetricia y Ginecología, Hospital Clínico de la Universidad de Chile, Independencia 999, 838-0456 Independencia, Santiago, Chile

C. S. Miranda $(\square)$

Reproductive Medicine Division, University of Chile Clinical Hospital, Hernando de Aguirre 128, Of. 306, 751-0026 Providencia, Santiago, Chile

E-mail: gidenmir@mi.cl

Tel.: + 56-2-2344666

Fax: + 56-2-2343082 more difficult than laparotomy; the procedure requires 3-5 h of operative time [4]. The one-stitch technique described by Dubuisson and Swolin [5] approximates the fallopian tubes with a single layer suture of the entire wall, including both the muscle and the serosa in a short operative time [4]. We report a case of laparoscopic tubal anastomosis rapidly resulting in an intrauterine pregnancy, which delivered at term.

\section{Case report}

A 38-year-old woman, gravida 6, para 6 (three previous cesarean sections) requested reversal of tubal sterilization. She had conceived previously without difficulty. In 1994 she underwent tubal sterilization using the Pomeroy technique after cesarean delivery. The reason for requesting the reversal of tubal sterilization was the desire to have a child by a new husband. Normal semen analyses and normal ovulatory cycles were confirmed. Preoperative hysterosalpingography was performed and patency of the proximal portion of tubes was documented. There was no evidence of dye spilt into the peritoneal cavity. The patient underwent laparoscopic tubal reanastomosis in October 2002.

The patient was placed in the lithotomy position under general anesthesia, the bladder was emptied using a Foley catheter, and a uterine cannula was inserted for uterine manipulation and chromopertubation. A 12-mm trocar was introduced in the umbilical area; adequate pneumoperitoneum was achieved with $\mathrm{CO}_{2}$ gas. A 0degree laparoscope was inserted and the pelvic cavity was inspected. One $5.5-\mathrm{mm}$ trocar was placed in the suprapubic area and two were positioned laterally. The trocars were introduced sufficiently distally from the pubis so that movements with the forceps and needle holder would not be hindered. The total length of the right tube was $5 \mathrm{~cm}$ and the left tube was $3 \mathrm{~cm}$. The surgeon decided to perform right tubal anastomosis because the right tube was longer. We used a technique similar to that described by Dubuisson and Swolin [5], 
but with some modifications, as described by Bissonnette et al. [4]. First, the proximal stump was sectioned at the point of obstruction and the tubal opening was identified by injection of methylene blue through the uterine manipulator. The occluded end of the distal tube was raised with forceps and cut perpendicularly to avoid the underlying vessels. The suture materials, approximately $15 \mathrm{~cm}$ in length, were introduced through the 5.5$\mathrm{mm}$ left lateral trocar into the peritoneal cavity. Using a 4-0 polyglactin (Vicryl; Ethicon, Somerville, NJ, USA), the distal portion of the mesosalpinx was sutured in an anterior-to-posterior direction and the proximal portion was sutured in a posterior-to-anterior direction, to obtain proper alignment of the two segments of the tube. To achieve alignment, the suture was placed as close as possible to the muscle layer immediately adjacent to the sectioned end of the tube. The suture was tied intracorporeally with three throws. The isthmic-isthmic anastomosis was carried out with a single additional stitch. A 5-0 polypropylene monofilament (Prolene; Ethicon) suture was used at the 12 o'clock site. The suture passed through the muscularis and came out through the serosa. Thorough pelvic irrigation removed blood clots and fibrin degradation products. Vasopressin was not used at any time. The complete procedure required $2 \mathrm{~h}$ of operative time. The patient was discharged the day after surgery. She conceived spontaneously 3 months later and delivered at term.

\section{Discussion}

At present, tubal sterilization is the most frequently used method of birth control worldwide. This trend has been greatly assisted by the spread of laparoscopic techniques. Despite all the precautions, a few treated women $(3-5 \%)$ request tubal sterilization reversal, especially when other determining factors are involved, such as disintegration of a couple's relationship and, as a result of remarriage, the desire for another pregnancy [6]. In the case reported, the patient had started a new relationship and desired a child with her new husband.

The emergence of in vitro fertilization as a treatment modality for patients with tubal disease has moved reconstructive tubal surgery out of the spotlight. In many instances, the higher success rates achieved with tubal reconstruction still make it the procedure of choice. Moreover, in vitro fertilization is an opportunity to get pregnant only in the month of treatment. A successful tubal anastomosis is an opportunity to get pregnant every month once surgery has been carried out.

Preliminary studies of laparoscopic tubal anastomosis have reported poor pregnancy rates [4]. Reich et al. [7] reported a series of 22 cases in 1993. The intrauterine pregnancy rate was $35 \%$. Today, the magnification obtained with newer laparoscopic video equipment is similar to that obtained with an operating microscope [4]. In 1999, Yoon et al. [8] reported 202 cases of tubal laparoscopic reanastomosis. The intrauterine pregnancy rate was $87.1 \%$. The mean $( \pm \mathrm{SD})$ operative time was $140.2 \pm 53.3 \mathrm{~min}$. The operative time was reduced to approximately $2 \mathrm{~h}$ with increased experience. Dubuisson and Swolin [5] reported their experience of single suture laparoscopic tubal reanastomosis. Bissonnette et al. [4] were able to reduce operative time to $72 \mathrm{~min}$ and almost all patients could be discharged on the day of operation and had no postoperative complications and good fertility outcomes. Laparoscopic tubal reanastomosis requires advanced endoscopic skills [9]. This advanced technique requires the surgeon to be experienced in tubal anastomosis by laparotomy and in the basic laparoscopic operative techniques [8]. In our case, using stateof-the-art equipment, the two-stitch technique, good surgical skills, and surgeons with a great deal of experience of anastomosis by laparotomy, laparoscopic reanastomosis could be done safely and successfully in a reasonable operative time.

Spivak et al. [10] found, like Winston [11], that the site of anastomosis significantly affected the eventual outcome. An $88 \%$ intrauterine pregnancy rate was achieved after isthmic-isthmic anastomosis. In our case, isthmic-isthmic anastomosis of the right tube was carried out.

The length of the oviduct after reconstruction has been shown to be directly related to pregnancy rates in cases of midsegment anastomosis. Silber and Cohen [12], in a group of 11 patients, found a subsequent pregnancy rate of $100 \%$ when at least one tube was $>5 \mathrm{~cm}$ in length and no pregnancies when the length was $<3 \mathrm{~cm}$. Rock et al. [13] demonstrated similar findings in patients sterilized by electrocautery. In our case only the right tube, which was $5 \mathrm{~cm}$ in length, was operated on. We did not perform it on the left tube, which was $3 \mathrm{~cm}$ in length.

Vasquez et al. [14] suggested that the results of reversal surgery are much better if the interval after sterilization is $<5$ years. Our patient presented after interval since sterilization of 8 years.

Robotically assisted laparoscopic tubal reanastomosis may prove to combine the advantages of open microsurgery and laparoscopy without the disadvantages associated with abdominal incision, exposure of the pelvic viscera, and compromised precision in laparoscopy. The robotic arms and the unique design of the instruments with intraabdominal articulation give the surgeon all necessary degrees of freedom, allowing performance of complex movements in a limited space. The computer eliminates unintentional small hand movements and tremors [15].

\section{References}

1. Gomel V (1978) Profile of women requesting reversal of sterilization. Fertil Steril 30:39-40

2. Kjer JJ (1990) Regret of laparoscopic sterilization. Eur J Obstet Gynecol Reprod Biol 35:205-210

3. Gomel V (1995) From microsurgery to laparoscopic surgery; a progress. Fertil Steril 63:464-468 
4. Bissonnette F, Lapensée L, Bouzayen R (1999) Outpatient laparoscopic tubal anastomosis and subsequent fertility. Fertil Steril 72:549-552

5. Dubuisson JB, Swolin K (1995) Laparoscopic tubal anastomosis (the one stitch technique): preliminary results. Hum Reprod 10:2044-2046

6. Barjot PJ, Marie G, Von Theobald P (1999) Laparoscopic tubal anastomosis and reversal of sterilization. Hum Reprod 14:1222-1225

7. Reich H, McGlynn F, Parente C, Sekel L, Levie M (1993) Laparoscopic tubal anastomosis. J Am Assoc Gynecol Laparosc 1:16-19

8. Yoon TK, Sung HR, Kang HG, Cha SH, Lee CN, Cha KY (1999) Laparoscopic tubal anastomosis: fertility outcome in 202 cases. Fertil Steril 72:1121-1126

9. Chapron C, Devroey P, Dubuisson JB, Pouly JL, Vercelini P (1997) European Society for Human Reproduction and Embryology, Committee of Special Interest Group on Reproductive Surgery. ESHRE guidelines for training, accreditation and monitoring in gynecological endoscopy. Hum Reprod $12: 867-868$

10. Spivak MM, Librach CL, Rosenthal DM (1986) Microsurgical reversal of sterilization: a six-year study. Am J Obstet Gynecol 154:355-361

11. Winston R (1980) Reversal of tubal sterilization. Clin Obstet Gynecol 23:261

12. Silber SJ, Cohen R (1980) Microsurgical reversal of female sterilization: the role of tubal length. Fertil Steril 33:598

13. Rock JA, Bergquist CA, Zacur HA, Parmley TH, Guzick DFS, Jones HW (1982) Tubal anastomosis following unipolar cautery. Fertil Steril 37:613

14. Vasquez G, Winston R, Boeckx W, Brosens I (1980) Tubal lesions subsequent to sterilization, and the relation to fertility after attempts at reversal. Am J Obstet Gynecol 138:86

15. Degueldre M, Vandromme J, Huong PT, Cadière GB (2000) Robotically assisted laparoscopic microsurgical tubal reanastomosis: a feasibility study. Fertil Steril 74:1020-1023 